NBER WORKING PAPER SERIES

\title{
INFLATION TARGETING, PRICE-PATH TARGETING AND OUTPUT VARIABILITY
}

\author{
Stephen G. Cecchetti \\ Junhan Kim \\ Working Paper 9672 \\ http://www.nber.org/papers/w9672
}

\section{NATIONAL BUREAU OF ECONOMIC RESEARCH 1050 Massachusetts Avenue Cambridge, MA 02138}

May 2003

This paper was prepared for the N.B.E.R. Conference on Inflation Targeting, January 23-25, 2003 in Bal Harbour Florida. We wish to thank our discussant Greg Mankiw; as well as Edwin Truman and Mark Wynne for providing us with data; and Bill Gavin, Stefan Krause, Lianfa Li, Roisin O'Sullivan and the conference participants, especially Lars Svensson, for helpful suggestions. The views expressed herein are those of the authors and not necessarily those of the National Bureau of Economic Research.

(C)2003 by Stephen G. Cecchetti and Junhan Kim. All rights reserved. Short sections of text not to exceed two paragraphs, may be quoted without explicit permission provided that full credit including Cnotice, is given to the source. 
Inflation Targeting, Price-Path Targeting and Output Variability

Stephen G. Cecchetti and Junhan Kim

NBER Working Paper No. 9672

May 2003

JEL No. E5

\section{ABSTRACT}

The dramatic improvement in macroeconomic outcomes during the 1990s - stable, low inflation and high, stable growth - can be at least partly ascribed to improved monetary policy. Central banks became more independent and many of them adopted inflation targeting. This paper examines the potential for further improvements by refining the concept of inflation targeting. We construct a general model that encompasses a broad array of possible target regimes, and apply it to the data. Our results suggest that the vast majority of countries could benefit from moving to pricepath targeting, where the central bank makes up for periods of above (below) target inflation with later periods of below (above) target inflation.

Stephen G. Cecchetti

Department of Economics

Ohio State University

Columbus, Ohio 43210

and NBER

cecchetti.1@osu.edu
Junhan Kim

Department of Economics

Ohio State University

Columbus, Ohio 43210

kim.1052@osu.edu 


\section{Introduction}

The 1990s were amazing in many ways. Not only did the internet and cellular phones come into widespread use, but overall economic conditions improved nearly everywhere we look. Growth was higher, inflation was lower, and both were more stable. In the U.S., for example, inflation fell from 6 percent at the beginning of the decade to less than 2 percent by the end. Meanwhile real growth rose from less than 3 percent to over 4 percent. And volatility declined, too. The American case is the most dramatic of what has really been a world-wide trend. ${ }^{1}$ And while these improvements in economic performance could have been the consequence of the world being calmer, Cecchetti, Flores-Lagunes and Krause (2002) argue that roughly three-quarters of it can be explained by better monetary policy. That is, central bankers did a better job of stabilizing inflation at low levels while keeping growth high.

Making better monetary policy is not just a problem of finding compentent central bankers. In fact, there is a history of central bankers who tried to do their jobs, but were thwarted by politicians. Over the years we have learned that the institutional environment is at least as important as the people in insuring good policy outcomes. Without a well-designed central bank, the people in charge don't have a chance. Today, we have a good sense of what best practice is in the design of central banks. First, it is crucial that monetary policymakers are independent of short-term political influences. Second, these independent central bankers must be held accountable through mechanisms that involve public announcement of objectives. Inflation targeting is the most common formulation of the sort of policy regime in place today. ${ }^{2}$ The primary element of inflation targeting is a public commitment to price stability in the form of a medium-term numerical inflation target.

\footnotetext{
${ }^{1}$ Cecchetti and Ehrmann (2002) compare the 1985 to 1989 period with 1993 to 1997 for a set of 23 industrialized and emerging market countries and find that annual inflation fell by an average of five percentage points, annual growth rose by an average of one percentage point, and both were significantly more stable.

${ }^{2}$ For a brief synopsis of what inflation targeting entails see Mishkin (forthcoming).
} 
With the success of inflation targeting has come a discussion of potential refinements. One issue is whether the central bank should adopt a target for inflation or a target for the path of the price level. With an inflation target, the central bank simply tries to insure that period-by-period inflation remains close to the target. When inflation turns out to be above or below the target, the miss is forgotten. Bygones are bygones, so there is a form of base drift in the (log) price level. Price-path targeting, or "price-level targeting" as it is often called, is different as it implies that when the the price level is above or below the target path, the objective of policy is to return it to the preset target path. ${ }^{3}$ This means that if prices move above the target path, then policy will need to bring them back down. ${ }^{4}$ But which one is better? Should central banks be instructed to target inflation or target the price path?

Svensson (1999) is the first person to take on this question. He starts by assuming that society actually cares about inflation. The social objective is to minimize the expected present discounted value of the weighted average of squared deviations of inflation and output from their targets. He then posits that the central bank can be bound to meet a particular objective, but not to respond to shocks in a specific way. That is, the central bank will always have discretion in adjusting its instrument, but it can be held accountable for its objective. This sort of discretion, what we might refer to as "instrument discretion," implies that if we were to instruct central bankers to minimize the true social loss function, there would be a bias. The exact form of the bias depends on the structure of the economy, but in most cases there is a bias toward stabilizing output. ${ }^{5}$ One solution to this problem is to instruct the central bank to minimize a loss function that deviates from society's. Rogoff (1985) suggested appointing central bankers that are more avid inflation hawks than the

\footnotetext{
${ }^{3}$ We adopt the terminology price-path targeting rather than the traditional price-level targeting to emphasize that the target path can have a positive slope and so a period of inflation need not be countered with one of deflation.

${ }^{4}$ Mervyn King (1999) argues that in practice there is little difference between inflation targeting and price-path targeting. The reason is that politicians will hold central bankers accountable for meeting inflation targets over sufficiently long horizons, that it will look like a price-path target. We will take this up in more detail below.

${ }^{5}$ For a discussion see Clark, Goodhart and Huang (1999).
} 
public at large.

In this context, Svensson shows that in countries where output is sufficiently persistent, performance can be improved by instructing policymakers to target the price path, even though society cares about inflation. ${ }^{6}$ To understand why output persistence is central to the result, note that the more persistent output is, the longer output stays away from equilibrium following a disturbance. Now consider the possibility of a policy response. Monetary policy responds to shocks by inducing a price-level surprise, immediately creating a conflict between the output and inflation stability objectives. And the more persistent output is, the longer lasting the shocks and the more important it will be to aggressively respond to them. If the goal is to stabilize prices, then these agressive responses will have to be undone quickly, which ends up lowering the volatility of inflation.

There are several issues that arise in considering this result. First, Svensson compares inflation targeting with price-path targeting in order to emphasize the contrast between in two. But there are really a continuum of intermediate possibilities that weight the two. Batini and Yates (2001) have labeled these "hybrid-targeting" regimes. We begin by showing that for a given degree of output persistence, there is an optimal hybrid-targeting policy that is a weighted average of inflation and pricepath targeting. But second, and more importantly, the focus on output persistence means that the choice is an empircial one. What is the optimal regime for a given country? And beyond this, there is the question of whether it is worth trying to move to the optimal regime. Clarity is and should be highly prized in central banking.

In fact, an optimal hybrid target sacrifices simplicity for optimality. It is much difficult to explain a hybrid than it would be to explain either of the extreme alternatives. However, as King (1999) has suggested, one of the key policy choices is the horizon over which central bankers are evaluated. That is, are they asked to maintain

\footnotetext{
${ }^{6}$ More recent papers by Dittmar and Gavin (2000), and Vestin (2000) confirm this result.
} 
inflation at or near the target level on average every two, three, five or even ten years? Put another way, central bankers will have an horizon over which they are expected to bring the price level back to its desired path. Under this interpretation, hybridtargeting becomes a statement about the optimal horizon over which the price level is brought back to the desired path, it may not that hard to convince people that they should give the central bank some time to fight back unwanted price shocks.

Even so, the idea that central bankers should, for strategic reasons, be told to do something that explicitly deviates from what society truly cares about will trouble many people. Should we go to the trouble of explaining that we are instructing the central bank to do one thing, while we care about another because we know that they can't be trusted? Again, this is an empirical question. How much do we lose by just telling monetary policymakers to target the thing that society cares about?

To address these issues, we examine a set of 23 countries and find that for nearly all of them some form of hybrid-targeting regime would be optimal - at least in principle. But we go on to show that adopting such an optimal regime has only very modest benefits (as measured by the percentage reduction in the social loss) when compared with strict inflation targeting. In other words, once you look at the numbers closely it is hard to see the benefit of starting to engage in what would surely be a very difficult public dialogue. Our conclusion is that we should hold central bankers accountable for meeting our social loss function, not some contrived one that might incrementally improve macroeconomic performance.

The remainder of this paper is organized as follows. First, we set out the theoretical problem and derive the optimal hybrid-targeting regime. And we show that this can be interpreted as the optimal horizon. We also show the relationship between output persistence and the weight on price stability. And we presents a set of empirical results, compare the loss between optimal targeting regime and inflation or price-paths targeting, and the final section concludes. 


\section{$2 \quad$ Hybrid Targeting}

The theoretical exercise is straightforward. Society cares about a weighted average of inflation and output deviations from their target paths. If it were possible to bind policymakers to react to shocks in a particular way, then it would be optimal to give them society's objective and then hold them accountable for adjusting their policy instrument in the way prescribed by the reaction function that minimizes this social objective. But such commitment is impossible (and may not even be desirable). Instead, the central bank can be held accountable for minimizing a loss function under discretion. What should that loss function be?

To answer this question, we proceed in two steps. First, we derive the central bank's policy reaction function, or instrument rule, under discretion for a family of loss functions that admits a wide variety of targeting regimes. Second, given the solution we find the targeting regime that minimizes the social loss. This is the optimal hybrid.

\subsection{The Central Banker's Problem}

The policymaker solves a standard optimal control problem, choosing the path of the price level that minimizes a quadratic loss function subject to the constraints imposed by the linear structure of the economy. We assume that the central bank minimizes

$$
L^{C B}=E\left\{\sum_{t} \beta^{t}\left[\lambda\left(p_{t}-p_{t}^{*}\right)^{2}+(1-\lambda)\left(y_{t}-y_{t}^{*}\right)^{2}\right]\right\}
$$

where $p_{t}$ is the (log)actual price level, $p^{*}$ is the desired price level, $y_{t}$ is the (log)actual output, $y^{*}$ is desired(or potential) output level, $\lambda$ is the degree to which the central 
bank prefers price stability to output stability, and $\beta$ is the time discount factor. Equation (1) is sufficiently general to admit inflation targeting, price-path targeting, and everything in between. Targeting regimes differ depending on how the target, $p_{t}^{*}$, is defined. The simplest cases are inflation targeting, where

$$
p_{t}^{*}(I T)=p_{t-1}+\pi^{*}
$$

and price-path targeting, where

$$
p_{t}^{*}(P P T)=p_{t-1}^{*}+\pi^{*}
$$

In both cases the "inflation target" is $\pi^{*}$. But under inflation targeting, given by (2), the target is an increment over the past period's realized price level, whatever it turned out to be. By contrast, under price-path targeting, the current target is an increment over the past period's target.

Hybrid targeting is a weighted average of inflation and price-path targeting. That is,

$$
\begin{aligned}
p_{t}^{*}(\text { Hybrid }) & =\eta\left(p_{t-1}+\pi^{*}\right)+(1-\eta)\left(p_{t-1}^{*}+\pi^{*}\right) \\
& =\eta p_{t-1}+(1-\eta) p_{t-1}^{*}+\pi^{*}
\end{aligned}
$$

where $\eta$ is the weight on inflation targeting. Notice that $\eta=1$ and $\eta=0$ are the special cases of inflation and price- path targeting. Substituting (4) into the loss function (1), and normalizing various constants and initial conditions to zero, we get

$$
L^{C B}=E\left\{\sum_{t} \beta\left[\lambda\left(p_{t}-\eta p_{t-1}\right)^{2}+(1-\lambda) y_{t}^{2}\right]\right\}
$$

Normalization implies that $y$ is now the output gap, and that the price path is now measured as the deviation from the inflation objective $\pi^{*}$. 
Following Svensson (1999) and others, we assume that the dynamics of the economy are adequately described by a Neo-Classical Phillips Curve. ${ }^{7}$ That is,

$$
y_{t}=\rho y_{t-1}+\alpha\left(p_{t}-p_{t}^{e}\right)+\epsilon_{t}
$$

where $p_{t}^{e}$ is the expectation of $p$ at time t, $\rho$ and $\alpha$ are constants and $\epsilon$ is an i.i.d. shock with variance $\sigma_{\epsilon}^{2}$. For the points that we wish to make here, this closed economy model is sufficient. In the empirical section, we expand the analysis to an open-economy version that includes import prices as well.

The job of the central bank is to choose a path for the price level $p_{t}$ that minimizes the loss (5) subject to (6). ${ }^{8}$ Assuming rational expectations, we can use the techniques described in Svensson $(1997,1999)$ to first derive the first order conditions, guess the solution and then use the method of undetermined coefficients. ${ }^{9}$ The first order conditions include the output equation (6) and

$$
p_{t}-\eta p_{t-1}=-\frac{\alpha(1-\lambda)(1-a \rho \beta)}{\lambda[1-\rho \beta(\rho-b \alpha)](1-\eta \rho \beta)} y_{t} .
$$

Equation (7) embodies the trade-off between output and prices in the loss function. It tells us the extent to which prices react to output shocks along an optimal path. Under rational expectations, we know that the solution for the price level must be of the form

$$
p_{t}=a p_{t-1}+b y_{t-1}+c \epsilon_{t}
$$

\footnotetext{
${ }^{7}$ We choose the Neo-Classical Phillips Curve because of its theoretical tractability. There are a number of alternatives, including the now common New-Keynesian Phillips Curve in which the output gap depends on expected-future prices rather than current ones, and the aggregate supply formulation dervided by Mankiw and Reis (2001) in their work on sticky information. While it would be feasible to examine these alternatives numerically, the more conventional Phillips Curve allows us to derive a wider range of conclusions.

${ }^{8}$ By adding an aggregate demand curve relating the price level to the interest rate, we could shift the problem to one in which the central bank does not choose prices directly. This increase in complexity changes none of our results.

${ }^{9}$ See also Söderlind(1999).
} 
We can solve this for

$$
\begin{aligned}
a & =\eta \\
b & =\frac{-\left(1-\rho^{2} \beta\right)+\sqrt{\left(1-\beta \rho^{2}\right)^{2}-4 \rho^{2} \alpha^{2} \beta \frac{1-\lambda}{\lambda}}}{2 \rho \beta \alpha} \\
c & =-\frac{D}{1+\alpha D}, \\
\text { where } D & =\frac{\alpha(1-\lambda)}{\lambda[1-\rho \beta(\rho-b \alpha)]} .
\end{aligned}
$$

Setting $\eta$ equal to either zero or one, this solution collapses to the one in Svensson (1999).

This formulation allows us to write the laws of motion for output and prices, and these are

$$
\begin{aligned}
& y_{t}=\rho y_{t-1}+(1+\alpha c) \epsilon_{t} \\
& p_{t}=\eta p_{t-1}+b y_{t-1}+c \epsilon_{t} .
\end{aligned}
$$

That is, output depends on lagged output, while prices depend on both lagged prices and lagged output.

As others have noted, for a solution to the central bankers problem to exist, the coefficient on lagged output in the price equation, $b$, must have a real value. That is, a solution exists if and only if

$$
\frac{1-\lambda}{\lambda} \leq \frac{\left(1-\beta \rho^{2}\right)^{2}}{4 \rho^{2} \alpha^{2} \beta} .
$$

As Parkin (2000) points out, this condition is somewhat restrictive, since only large values of $\lambda$ are consistent with high persistence in output ( $\rho$ close to one). This means that if $\lambda$ is low and $\rho$ is high, there is no solution. The reason is that, under these circumstances the optimal response to stabilize output requires very high, even 
infinite volatility of price level (or inflation). ${ }^{10}$ Fortunately, most estimates that we know of suggest that central banks place much higher weight on inflation than they do on output volatility. For example, Cecchetti and Ehrmann (1999) estimate $\lambda$ 's for a number of countries, and most of them are $\frac{3}{4}$ or higher. So we view this problem as unlikely to occur in practice.

\subsection{Society's Problem}

With a complete characterization of the central bank's problem in hand, we can now turn to society's problem: What value of $\eta$ should monetary policymakers be instructed to use? To figure this out, all we need to do is find the value of $\eta$ that minimizes the social loss function, taking account of the central banker's behavior. Recall that we assume society minimizes a weighted average of inflation and output variability. We can write this as

$$
L^{S}=\lambda \sigma_{\pi}^{2}+(1-\lambda) \sigma_{y}^{2}
$$

For now we look only at the case in which $\lambda$ is the same for society and the central bank. Using the previous results, we can write this as

$$
L^{S}=\left[D^{2} \frac{2 \lambda(1-\rho)}{(1+\eta)(1-\rho \eta)}+(1-\lambda)\right]\left[\frac{1}{1-\rho^{2}}\left(\frac{c}{D}\right)^{2}\right] \sigma_{\epsilon}^{2} .
$$

Taking the derivative with respect to $\eta$ (noting that $D$ is not a function of $\eta$ and assuming that the condition (11) holds) yields the optimal hybrid-targeting regime:

$$
\eta^{*}=\frac{1-\rho}{2 \rho}
$$

\footnotetext{
${ }^{10} \mathrm{As}$ we show in the appendix, this is a problem that only arises under discretion. If the central bank can be forced to commit to an instrument rule, then the problem always has a solution.
} 
The result tells us that as $\rho$ approaches 1 , so that the shocks to output are extremely persistent, $\eta^{*}$ goes to zero. As $\rho$ shrinks, $\eta^{*}$ grows, but we assume that it can never exceed one. Importantly, the expression is consistent with Svensson's result. He shows that if one is restricted to choosing $\eta=0$ or $\eta=1$, then the threshold is at $\rho=0.5$.

Before proceeding, we note that under commitment, where society can bind policymakers not just to an objective function but to an instrument rule as well, the best thing to do is to give the central bank society's loss function. That's not at all surprising. What is surprising is that if society's loss is in terms of the price path rather than inflation, that is $L^{S}$ is a function of $\sigma_{p}^{2}$ rather than $\sigma_{\pi}^{2}$, then the discretionary solution is the same as the commitment solution. ${ }^{11}$

\subsection{Stabilization Bias}

So far, we have been concerned with the benefits to be obtained from giving the central bank a hybrid target. But in addition to choosing $\eta^{*}$, society has the option of giving the central bank a $\lambda$ that deviates from its own. The incentive for doing this comes from the fact that, left to their own devices, central bankers may choose to stabilize output more than is socially optimal. Avoiding this stabilization bias requires setting $\lambda^{C B}$ above $\lambda^{S}$.

To see how this works, we return to equation (13) and note first that the $\lambda$ 's here represent social preferences and that the $D$ (defined in the previous section) is a function of the central bank's $\lambda$. Using this, we can rewrite the expression for the

\footnotetext{
${ }^{11}$ If inflation's primary cost is that it makes long-term planning difficult, then this may be the case we should all be focusing on. See the appendix for details.
} 
social loss as:

$$
L^{S}=\left[D\left(\lambda^{C B}\right)^{2} \frac{2(1-\rho) \lambda^{s}}{(1+\eta)(1-\rho \eta)}+\left(1-\lambda^{s}\right)\right]\left[\frac{1}{1-\rho^{2}}\left(\frac{1}{1+\alpha D\left(\lambda^{C B}\right)}\right)^{2}\right] \sigma_{\epsilon}^{2} .
$$

This change has no impact on the degree of optimal hybrid targeting. $\eta^{*}$ was not a function of $\lambda$ before, and it isn't now. But minimizing (15) requires not only finding $\eta^{*}$, but also figuring out what $\lambda^{C B}$ should be as well. The first-order condition for this second choice is given by

$$
\frac{\alpha\left(1-\lambda^{C B}\right)}{\lambda^{C B}} f(\rho)=\frac{\alpha\left(1-\lambda^{s}\right)}{\lambda^{s}}
$$

where $f(\cdot)$ is an increasing function of $\rho$. So with given $\lambda^{s}$, as $\rho$ rises, $\lambda^{C B}$ rises as well.

Figure (1) plots the relationship between output persistence and $\lambda^{C B}$ when $\lambda^{s}$ is 0.5 and 0.8 . Throughout we assume that $\eta$ is set at the optimal level, $\eta^{*}$ in equation (14). The result is clear: the more persistent output is, the more conservative the central banker should be. And as the output approaches a random walk, the closer $\lambda^{C B}$ gets to one.

This is a good place to make another important point. In the last section we noted that there are times when the discretionary solution to the central banker's problem does not exist. Looking back at the restriction (11) required for existence, we see that there is always a solution when $\lambda$ is big enough. So, if we are concerned that $\rho$ may be high, we can avoid potential difficulties by instructing the central banker to care almost exclusively about inflation. 
Figure 1: Central Bank's $\lambda$
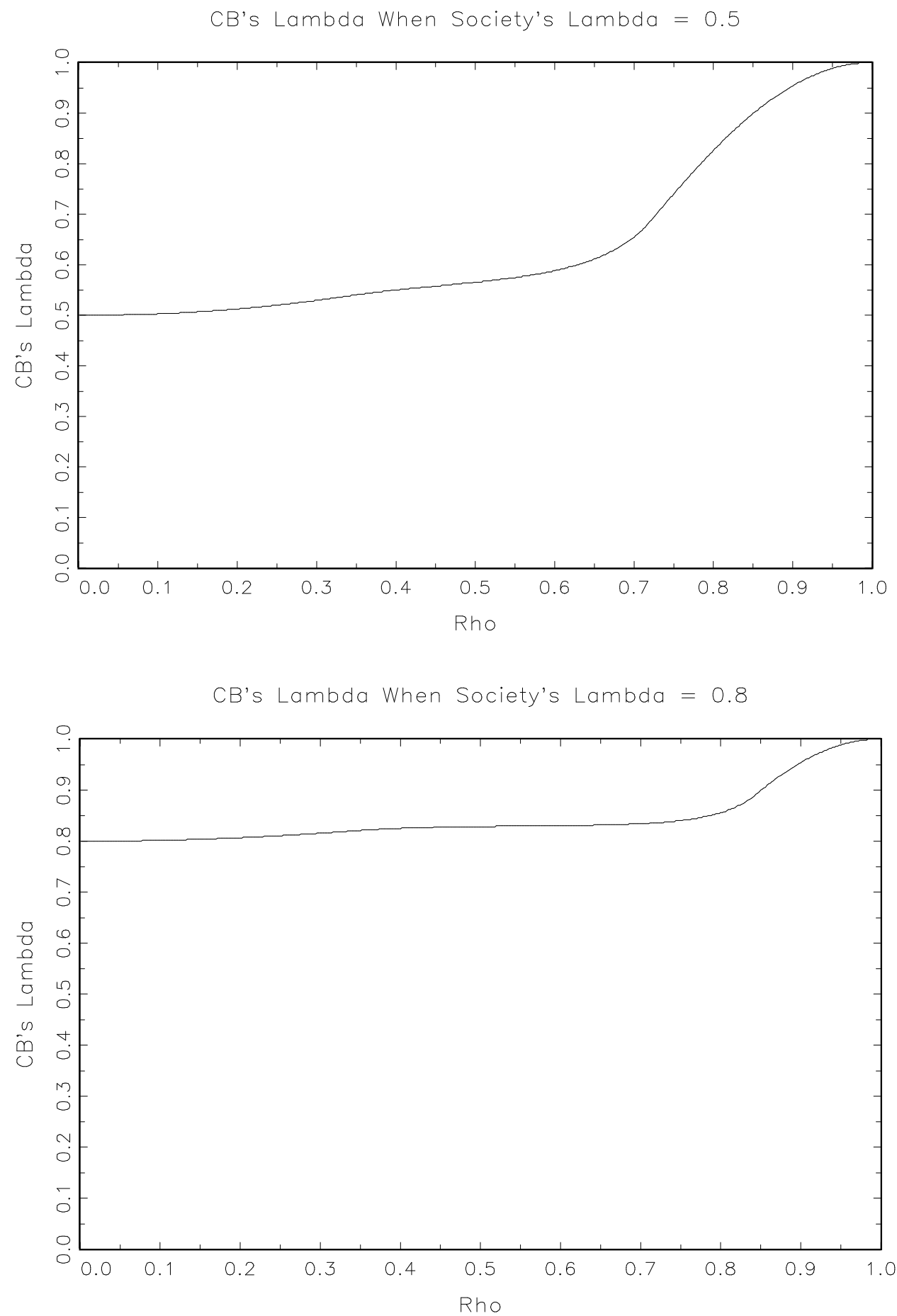


\section{Empirical Results}

We now see that the optimal hybrid-targeting regime - the degree to which the central bank should target inflation relative to targeting the path of the price level depends on how persistent output is. This leads us to ask how persistent is output and how close is the actual behavior of prices to what it would be under an optimal targeting regime? The task of this section is to bring data to bear on these questions.

We do this in three steps. First, we estimate an empirical analog of the closedeconomy model we studied in Section 2. Second, since a number of countries we consider are small open economies, we introduce external factors into the estimation. Finally, we posit a social loss function in order to do welfare comparisons and measure the gains from adopting an optimal hybrid target.

\subsection{Closed Economy}

Our strategy is the following. Using quarterly data on consumer prices and industrial production, we estimate equations (9) and (10). ${ }^{12}$ (The data are all described in the Appendix.) Taking account of the serial correlation in output, we use the following specifications:

$$
\begin{aligned}
& y_{t}=\rho y_{t-1}+\sum_{i=1}^{4} \gamma_{i} \Delta y_{t-i}+e_{1 t} \\
& p_{t}=\eta p_{t-1}+b_{1} y_{t-1}+b_{2} y_{t-2}+b_{3} y_{t-3}+b_{4} y_{t-4}+e_{2 t},
\end{aligned}
$$

where $y$ is computed as the deviation of log output from Hodrick-Prescott filtered output, and $p$ measures the deviation of the log price level from a measure of the

\footnotetext{
${ }^{12}$ We note that our exact results are not invariant to the choice of the frequency of the data.
} 
target. During the periods when countries were employing inflation targets, we used the target itself for this computation. ${ }^{13}$ In the absence of an inflation target, we used a Hodrick-Prescott filter.

The results for both the full sample (1980s and 1990s), and just the last decade are reported in Table 1 and Table 2. Estimates range widely. ${ }^{14}$ The first table shows estimates of $\rho$, together with standard errors. The important thing to notice is that $\rho$ ranges from a low of 0.29 to a high of 0.82 , and that it is unstable across time periods. Both the range and instability have important implications for policy, and so we will return to them later. ${ }^{15}$

Table 2 reports our estimates of the optimal hybrid-targeting regime, this is $\hat{\eta}^{*}$, as well as the estimate that is implied by the actual behavior of prices in each country, this is $\tilde{\eta}$. Our estimates of $\rho$ suggest that a number of countries should be putting significant weight on the price path, $\hat{\eta}^{*}<<1$, but virtually all of them exhibit behavior that is closer to inflation targeting, $\tilde{\eta} \approx 1$. Given these estimates, we test whether $\tilde{\eta}=\eta^{*}$ and the answer is no. The p-value is reported in the 3rd and 6th column of Table $2 .^{16}$

\footnotetext{
${ }^{13}$ For the cases in which we have data for an explicit inflation target, we compute the price-path target as $p_{t}^{*}=\log \left(C P I_{t-1}\right)+\pi^{*}$, where $\pi^{*}$ is the annual inflation target. Details are in the data appendix.

${ }^{14}$ All estimates throughout the paper are median-bias corrected using the empirical distributions that are also used to compute the standard errors.

${ }^{15}$ While we report results for an HP filter with parameter set to the standard 1600, experimentation in the range from 800 to 3200 leave the character of our results unchanged.

${ }^{16}$ Using a nonparametric bootstrap, we compute the empirical distribution of $\hat{\eta}^{*}$ and then report the p-value for $\tilde{\eta}$ in that distribution.
} 
Table 1: Output Persistence: The Closed Economy Case

\begin{tabular}{l|cc|cc}
\hline \hline & \multicolumn{2}{|c|}{ Full Sample } & \multicolumn{2}{|c}{ 1990s } \\
Country & $\hat{\rho}$ & s.e. & $\hat{\rho}$ & s.e. \\
\hline \hline Australia & 0.64 & $(0.10)$ & 0.49 & $(0.18)$ \\
Austria & 0.76 & $(0.19)$ & 0.66 & $(0.36)$ \\
Canada & 0.73 & $(0.06)$ & 0.74 & $(0.09)$ \\
Chile & 0.57 & $(0.21)$ & 0.47 & $(0.43)$ \\
Denmark & 0.56 & $(0.14)$ & 0.31 & $(0.23)$ \\
Finland & 0.78 & $(0.07)$ & 0.65 & $(0.13)$ \\
France & 0.61 & $(0.15)$ & 0.61 & $(0.15)$ \\
Germany & 0.70 & $(0.10)$ & 0.61 & $(0.17)$ \\
Ireland & 0.56 & $(0.12)$ & 0.50 & $(0.19)$ \\
Israel & 0.56 & $(0.09)$ & 0.29 & $(0.15)$ \\
Italy & 0.71 & $(0.10)$ & 0.63 & $(0.15)$ \\
Japan & 0.78 & $(0.05)$ & 0.69 & $(0.09)$ \\
Korea & 0.58 & $(0.10)$ & 0.60 & $(0.13)$ \\
Mexico & 0.64 & $(0.10)$ & 0.69 & $(0.15)$ \\
Netherlands & 0.64 & $(0.15)$ & 0.68 & $(0.23)$ \\
New Zealand & 0.58 & $(0.10)$ & 0.58 & $(0.15)$ \\
Norway & 0.43 & $(0.16)$ & 0.55 & $(0.19)$ \\
Portugal & 0.76 & $(0.08)$ & 0.69 & $(0.14)$ \\
Spain & 0.72 & $(0.07)$ & 0.70 & $(0.11)$ \\
Sweden & 0.71 & $(0.09)$ & 0.60 & $(0.13)$ \\
Switzerland & 0.33 & $(0.22)$ & 0.35 & $(0.33)$ \\
United Kingdom & 0.80 & $(0.07)$ & 0.78 & $(0.08)$ \\
United States & 0.76 & $(0.04)$ & 0.82 & $(0.06)$ \\
\hline \hline
\end{tabular}

Estimates $\hat{\rho}$ are small sample bias corrected autocorrelation coefficient from fourth-order autoregression using industrial production, equation (16). All data is quarterly data, seasonally adjusted and filtered using a Hodrick-Prescott filter. The full sample is 1980 Q1 to 2001 Q4 for non-euro-area countries. For countries in EMU, the sample ends in 1998 Q4. Standard errors (s.e.) are constructed from nonparametric bootstrap with 3000 replications. 
Table 2: The Optimal Hybrid-Targeting Regime: The Closed Economy Case

\begin{tabular}{l|ccc|ccc}
\hline \hline \multirow{2}{*}{ Country } & \multicolumn{3}{|c|}{ Full Sample } & \multicolumn{3}{c}{ 1990s } \\
& $\hat{\eta}^{*}$ & $\tilde{\eta}$ & $\begin{array}{c}\text { p-value testing } \\
\text { p-value testing }\end{array}$ & & \multicolumn{3}{c}{$\eta^{*}$} & $\hat{\eta}^{*}$ & $\tilde{\eta}$ & $\eta^{*}$ \\
\hline \hline Australia & 0.29 & 0.81 & 0.01 & 0.50 & 0.69 & 0.33 \\
Austria & 0.15 & 0.68 & 0.07 & 0.25 & 0.46 & 0.26 \\
Canada & 0.18 & 0.94 & 0.00 & 0.18 & 0.88 & 0.00 \\
Chile & 0.36 & 0.72 & 0.22 & 0.31 & 0.64 & 0.31 \\
Denmark & 0.39 & 0.67 & 0.17 & 1.00 & 0.24 & 0.14 \\
Finland & 0.14 & 0.91 & 0.00 & 0.26 & 0.84 & 0.03 \\
France & 0.31 & 0.80 & 0.08 & 0.32 & 0.80 & 0.08 \\
Germany & 0.21 & 0.83 & 0.00 & 0.32 & 0.67 & 0.15 \\
Ireland & 0.39 & 0.81 & 0.09 & 0.49 & 0.63 & 0.37 \\
Israel & 0.39 & 0.90 & 0.03 & 1.00 & 0.79 & 0.26 \\
Italy & 0.21 & 0.94 & 0.00 & 0.29 & 1.00 & 0.05 \\
Japan & 0.14 & 0.75 & 0.00 & 0.23 & 0.70 & 0.01 \\
Korea & 0.35 & 0.90 & 0.02 & 0.34 & 0.56 & 0.19 \\
Mexico & 0.28 & 0.86 & 0.01 & 0.23 & 0.83 & 0.05 \\
Netherlands & 0.28 & 0.88 & 0.06 & 0.24 & 0.60 & 0.17 \\
New Zealand & 0.36 & 0.93 & 0.03 & 0.36 & 0.54 & 0.25 \\
Norway & 0.64 & 0.77 & 0.39 & 0.38 & 0.56 & 0.32 \\
Portugal & 0.16 & 0.88 & 0.00 & 0.23 & 0.83 & 0.04 \\
Spain & 0.19 & 0.80 & 0.00 & 0.22 & 0.92 & 0.01 \\
Sweden & 0.21 & 0.84 & 0.00 & 0.33 & 0.53 & 0.21 \\
Switzerland & 1.00 & 0.89 & 0.44 & 0.89 & 0.87 & 0.36 \\
United Kingdom & 0.12 & 0.76 & 0.00 & 0.14 & 0.44 & 0.01 \\
United States & 0.16 & 1.00 & 0.00 & 0.11 & 0.91 & 0.00 \\
\hline \hline & & & & & & \\
\hline
\end{tabular}

Estimates of $\hat{\eta}^{*}$ are constructed using the $\hat{\rho}$ in Table 1. Estimates of $\tilde{\eta}$ are the coefficient on the lag of prices from equation (17). Data sources are all described in the appendix. The p-values for the tests are constructed using a nonparameteric bootstrap with 3000 replications. 


\subsection{Open Economy}

To take account of the fact that countries like Israel, Belgium and Ireland are small and open, we introduce external factors into our analysis. Following Svensson (1998), we introduce import prices into the Phillips Curve (6):

$$
y_{t}=\rho y_{t-1}+\alpha\left(p_{t}-p_{t}^{e}\right)+\phi_{y} p_{t}^{F}+\epsilon_{t},
$$

where $p_{t}^{F}$ is the foreign price level denominated in domestic currency. With this modification, all of the results in Section 2 go through, and we can rewrite empirical specification equations (9), (10) as

$$
\begin{aligned}
& y_{t}=\rho y_{t-1}+\sum_{i=1}^{4} \gamma_{i} \Delta y_{t-i}+\phi_{y} p_{t}^{F}+e_{1 t} \\
& p_{t}=\eta p_{t-1}+b_{1} y_{t-1}+b_{2} y_{t-2}+b_{3} y_{t-3}+b_{4} y_{t-4}+\phi_{p} p_{t}^{F}+e_{2 t}
\end{aligned}
$$

Table 3 reports estimates of output persistence, $\rho$, after accounting for these external factors. The results are very similar to those in Table 1 . The correlation between these 2 sets of estimates is 0.96 for full sample and 0.89 for 1990s, and the mean absolute difference between the estimates is 0.03 and 0.075 respectively. Looking at the estimates of the various measures of $\eta$ in Table 4, our conclusions from the closedeconomy analysis remain. In virtually every case, our estimate of the optimal hybrid target has $\eta$ well below one, closer to price-path targeting than inflation targeting, but the actual behavior of prices in these countries suggests something close to inflation targeting.

It is interesting to relate all of these results to what King (1999) referred to as an evaluation horizon for central bankers. He suggested that in practice an inflation targeting central bank will be evaluated on whether it met its target on average over some number of years. The evaluation horizon is related to the hybrid regime. The longer the period over which inflation is averaged, the closer the regime is to price- 
Table 3: Output Persistence: The Open Economy Case

\begin{tabular}{|c|c|c|c|c|}
\hline \multirow{2}{*}{ Country } & \multicolumn{2}{|c|}{ Full Sample } & \multicolumn{2}{|c|}{$1990 \mathrm{~s}$} \\
\hline & $\hat{\rho}$ & s.e. & $\hat{\rho}$ & s.e. \\
\hline Australia & 0.66 & $(0.09)$ & 0.58 & $(0.19)$ \\
\hline Austria & 0.84 & $(0.23)$ & 0.63 & $(0.50)$ \\
\hline Canada & 0.75 & $(0.06)$ & 0.73 & $(0.11)$ \\
\hline Chile & 0.61 & $(0.07)$ & $\mathrm{n} / \mathrm{a}$ & $(\mathrm{n} / \mathrm{a})$ \\
\hline Denmark & 0.61 & $(0.15)$ & 0.13 & $(0.31)$ \\
\hline Finland & 0.79 & $(0.05)$ & 0.78 & $(0.14)$ \\
\hline France & $\mathrm{n} / \mathrm{a}$ & $(\mathrm{n} / \mathrm{a})$ & 0.61 & $(0.17)$ \\
\hline Germany & 0.73 & $(0.11)$ & 0.69 & $(0.20)$ \\
\hline Irela & 0.48 & $(0.14)$ & 0.60 & $(0.22)$ \\
\hline Israel & 0.56 & $(0.09)$ & 0.15 & $(0.17)$ \\
\hline Italy & 0.73 & $(0.09)$ & 0.63 & $(0.13)$ \\
\hline Japan & 0.73 & $(0.04)$ & 0.59 & $(0.09)$ \\
\hline $\mathrm{K}$ & 0.67 & $(0.11)$ & 0.60 & $(0.12)$ \\
\hline $\mathrm{Me}$ & 0.67 & $(0.11)$ & 0.53 & $(0.21)$ \\
\hline Nethe & 0.65 & $(0.17)$ & 0.59 & $(0.29)$ \\
\hline New Zealand & 0.59 & $(0.10)$ & 0.64 & $(0.16)$ \\
\hline Norway & 0.46 & $(0.16)$ & 0.67 & $(0.21)$ \\
\hline Portugal & 0.78 & $(0.08)$ & 0.75 & $(0.18)$ \\
\hline Spail & 0.73 & $(0.05)$ & 0.74 & $(0.09)$ \\
\hline Swede & 0.74 & $(0.10)$ & 0.65 & $(0.16)$ \\
\hline Switze & 0.32 & $(0.24)$ & 0.18 & $(0.43)$ \\
\hline ingdom & 0.81 & $(0.07)$ & 0.79 & $(0.04)$ \\
\hline United States & 0.78 & $(0.03)$ & 0.84 & $(0.04)$ \\
\hline
\end{tabular}

See notes to Table 1 and the Appendix for data sources. 
Table 4: Optimal Hybrid-Targeting Regime: The Open Economy Case

\begin{tabular}{l|ccc|ccc}
\hline \hline Country & \multicolumn{3}{|c|}{ Full Sample } & \multicolumn{4}{c}{ 1990s } \\
& $\hat{\eta}^{*}$ & $\tilde{\eta}$ & $\begin{array}{c}\text { p-value testing } \\
\tilde{\eta}=\eta^{*}\end{array}$ & $\hat{\eta}^{*}$ & $\tilde{\eta}$ & $\begin{array}{c}\text { p-value testing } \\
\tilde{\eta}=\eta^{*}\end{array}$ \\
\hline \hline Australia & 0.26 & 0.82 & 0.01 & 0.37 & 0.70 & 0.20 \\
Austria & 0.09 & 0.52 & 0.09 & 0.29 & 0.38 & 0.32 \\
Canada & 0.17 & 0.95 & 0.00 & 0.19 & 0.90 & 0.00 \\
Chile & 0.20 & 0.57 & 0.17 & $\mathrm{n} / \mathrm{a}$ & $\mathrm{n} / \mathrm{a}$ & $\mathrm{n} / \mathrm{a}$ \\
Denmark & 0.31 & 0.52 & 0.20 & 1.00 & 0.30 & 0.37 \\
Finland & 0.13 & 0.89 & 0.00 & 0.14 & 0.83 & 0.01 \\
France & $\mathrm{n} / \mathrm{a}$ & $\mathrm{n} / \mathrm{a}$ & $\mathrm{n} / \mathrm{a}$ & 0.33 & 0.67 & 0.17 \\
Germany & 0.19 & 0.72 & 0.01 & 0.21 & 0.75 & 0.09 \\
Ireland & 0.53 & 0.78 & 0.27 & 0.32 & 0.71 & 0.20 \\
Israel & 0.39 & 0.90 & 0.02 & 1.00 & 0.80 & 0.23 \\
Italy & 0.19 & 0.83 & 0.01 & 0.25 & 0.90 & 0.07 \\
Japan & 0.18 & 0.71 & 0.00 & 0.35 & 0.70 & 0.06 \\
Korea & 0.26 & 0.86 & 0.02 & 0.29 & 0.48 & 0.26 \\
Mexico & 0.26 & 0.88 & 0.01 & 0.42 & 0.88 & 0.20 \\
Netherlands & 0.26 & 0.83 & 0.10 & 0.30 & 0.60 & 0.27 \\
New Zealand & 0.34 & 0.99 & 0.01 & 0.28 & 0.50 & 0.19 \\
Norway & 0.56 & 0.77 & 0.32 & 0.24 & 0.62 & 0.16 \\
Portugal & 0.14 & 0.85 & 0.00 & 0.16 & 0.85 & 0.04 \\
Spain & 0.18 & 0.78 & 0.00 & 0.17 & 0.90 & 0.01 \\
Sweden & 0.19 & 0.80 & 0.00 & 0.26 & 0.53 & 0.16 \\
Switzerland & 1.00 & 0.86 & 0.48 & 1.00 & 0.87 & 0.34 \\
United Kingdom & 0.11 & 0.76 & 0.00 & 0.13 & 0.44 & 0.00 \\
United States & 0.14 & 0.91 & 0.00 & 0.10 & 0.63 & 0.00 \\
\hline \hline
\end{tabular}

See notes for Table 2 and the Appendix for data sources. 
path targeting. Using this intuition, we can construct approximate measures of the horizon as $\left(\frac{1}{\eta}\right)$. For many countries we find that $\eta^{*}$ is between 0.2 and 0.3 , implying a horizon of between 3 and 4 quarters. To get a number that is usable in practice, we need to add another 4 to 6 quarters that it takes for policy changes to have an impact on prices and output. The implication is that the evaluation horizon should be in the range of 2 to 3 years.

Before continuing, note that we recomputed all of the results for both the closed and open economy versions of our model substituting core consumer prices for the headline measures used in Sections 3.1 and 3.2. Tables analogous to 2 and 4 are in the appendix. Overall, we find that the change in the price measure makes very little difference. Estimates of $\tilde{\eta}$ from the price equation are highly correlated between the two sets of matching results. For the full sample, the correlation for the 17 countries for which we have data is 0.79 for the closed economy model and 0.83 when import prices are included.

\subsection{Loss Comparison}

Simply computing the optimal value for $\eta$, the degree of a hybrid regime, is only the first step. What we really want to know is whether adopting the optimal hybrid makes any difference to welfare. Given the fact that estimates of $\eta$ are fairly imprecise, this question is particularly important. To address it, we construct estimates of the social loss, $L^{S}$, for different targeting regimes and compare them. Computing the loss requires that we choose a series of parameters. Before turning to the data, it is useful to look at some simulations. Using the theoretical results, we can estimate the extent of the welfare gain that comes from going from an inflation targeting regime to an optimal one. That is, we compare $L^{S}[\eta=1]$ with $L^{S}\left[\eta=\eta^{*}\right]$ for various values of the parameters of the model. Note that throughout this exercise, we assume that the preference parameter $\lambda$ is the same for society and the central bank. 
While it would be interesting to look across a wide range of values for the preference parameter $\lambda$, output persistence $\rho$ and the slope coefficient $\alpha$, the condition (11) places restrictions on the relationship among these. So instead, we look at a representative example. First, the restriction has a few simple properties: (1) Given $\alpha$, the higher $\rho$ the higher the minimum $\lambda$; and (2) Given $\rho$, the higher $\alpha$ the higher the minimum $\lambda$. What that means is that the more persistent output and the flatter the aggregate supply curve - that's the inverse of $\alpha$ in equation (6) - the higher the preference for inflation stability has to be for there to be a solution to the central bank's problem. To understand how restrictive this is, we have done a few simple calculations. Setting the discount factor $\beta=0.99$, we see that for $\alpha=0.5$ and $\rho=0.7$, $\lambda$ must be greater than 0.65 . As $\alpha$ decreases, the range of permissible values grows. So when $\alpha=0.3, \lambda$ can be as low as 0.4 for $\rho=0.7$. This creates a potential problem for the choice of $\alpha$. While we would like to work with relatively low values, we choose $\alpha=0.5$. This is the choice made by Dittmar, Gavin and Kydland (1999), who use estimates in Rudebusch and Svensson (1999) as justification.

Using these parameter values, we examine the improvement in the social loss for each country for two changes: (1) Moving from strict inflation targeting to the optimal hybrid regimes, that is $L^{S}[\eta *] / L^{S}[\eta=1]$; and (2) Shifting form a strict price-path targeting regime to the optimal hybrid, $L^{S}[\eta *] / L^{S}[\eta=0]$. Throughout we assume that the preference parameter $\lambda=0.8$ and the discount rate $\beta=0.99$. The results are somewhat sensitive to the choice of $\lambda$, but not to the choice of $\beta$. Looking at Table 5, we see that there is an important pattern. In no case does a move from price-path targeting to the optimal hybrid bring a sizable welfare gain. The same is not true of a move from inflation targeting. That is, the first and third columns include numbers that are far below one - e.g., 0.82 for Canada and 0.87 for Germany - while the second and fourth columns contain none.

It is worth examining this result in more detail. Figure 2 plots the two ratios $L^{S}[\eta *] / L^{S}[\eta=0]$ and $L^{S}[\eta *] / L^{S}[\eta=1]$ for a range of values for $\rho$ and $\lambda$, assuming 
Table 5: Loss Comparison

\begin{tabular}{l|cc|cc}
\hline \hline \multirow{2}{*}{ Country } & \multicolumn{2}{|c|}{ Full Sample } & \multicolumn{2}{|c}{$1990 \mathrm{~s}$} \\
& $L^{S}\left(\eta^{*}\right)$ & $L^{S}\left(\eta^{*}\right)$ & $L^{S}\left(\eta^{*}\right)$ & $L^{S}\left(\eta^{*}\right)$ \\
& $/ L^{S}(\eta=1)$ & $/ L^{S}(\eta=0)$ & $/ L^{S}(\eta=1)$ & $/ L^{S}(\eta=0)$ \\
\hline \hline Australia & 0.94 & 0.99 & 0.97 & 0.99 \\
Austria & $0.71^{*}$ & $0.71^{*}$ & 0.95 & 1.00 \\
Canada & 0.82 & 1.00 & 0.86 & 1.00 \\
Chile & 0.91 & 0.99 & $0.71^{*}$ & $0.71^{*}$ \\
Denmark & 0.96 & 0.99 & 1.00 & 0.96 \\
Finland & $0.71^{*}$ & $0.71^{*}$ & 0.72 & 1.00 \\
France & 0.96 & 0.99 & 0.96 & 0.99 \\
Germany & 0.87 & 1.00 & 0.91 & 0.99 \\
Ireland & 0.99 & 0.99 & 0.96 & 0.99 \\
Israel & 0.98 & 0.99 & 1.00 & 0.96 \\
Italy & 0.87 & 1.00 & 0.94 & 0.99 \\
Japan & 0.85 & 1.00 & 0.97 & 0.99 \\
Korea & 0.93 & 0.99 & 0.95 & 0.99 \\
Mexico & 0.93 & 0.99 & 0.98 & 0.99 \\
Netherlands & 0.96 & 0.99 & 0.97 & 0.99 \\
New Zealand & 0.96 & 0.99 & 0.95 & 0.99 \\
Norway & 0.99 & 0.99 & 0.93 & 0.99 \\
Portugal & 0.71 & 1.00 & 0.80 & 1.00 \\
Spain & 0.86 & 1.00 & 0.84 & 1.00 \\
Sweden & 0.86 & 1.00 & 0.94 & 0.99 \\
Switzerland & 1.00 & 0.97 & 1.00 & 0.98 \\
United Kingdom & $0.71^{*}$ & $0.71^{*}$ & $0.71^{*}$ & $0.71^{*}$ \\
United States & $0.71^{*}$ & $0.71^{*}$ & $0.71^{*}$ & $0.71^{*}$ \\
\hline \hline
\end{tabular}

Notes: Computations use $\alpha=0.5$ and $\lambda=0.8$, as well as the estimated value of $\rho$ reported in Table 1. Stars $\left(^{*}\right)$ indicate values of $(\alpha, \lambda, \rho)$ for which the restriction (11) is not met, and so the loss cannot be computed. The reported value is the minimum for which it can be computed. 
Figure 2: Loss comparing Targeting Regimes with Optimal Targeting

A. Comparing Price-Path Targeting to the Optimal Hybrid Regime $(\alpha=0.5)$

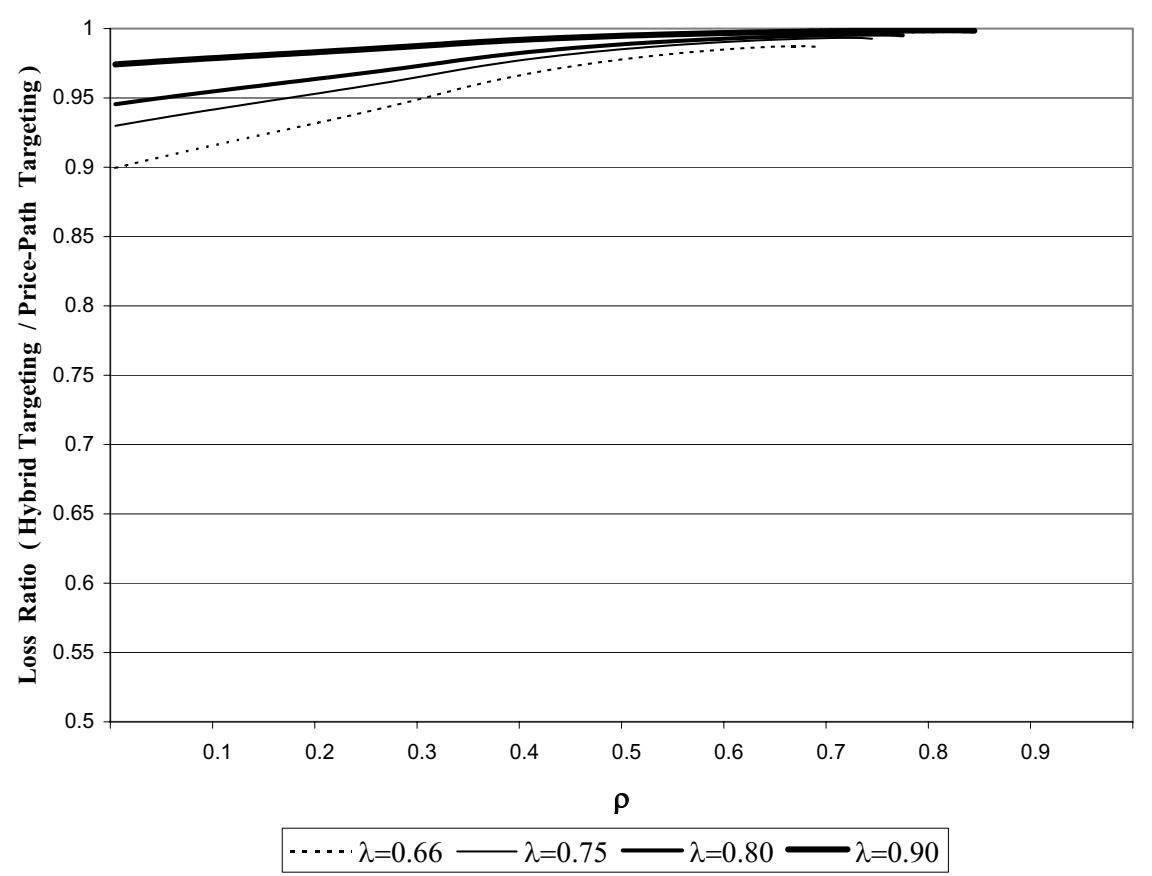

B. Comparing Inflation Targeting to the Optimal Hybrid Regime $(\alpha=0.5)$

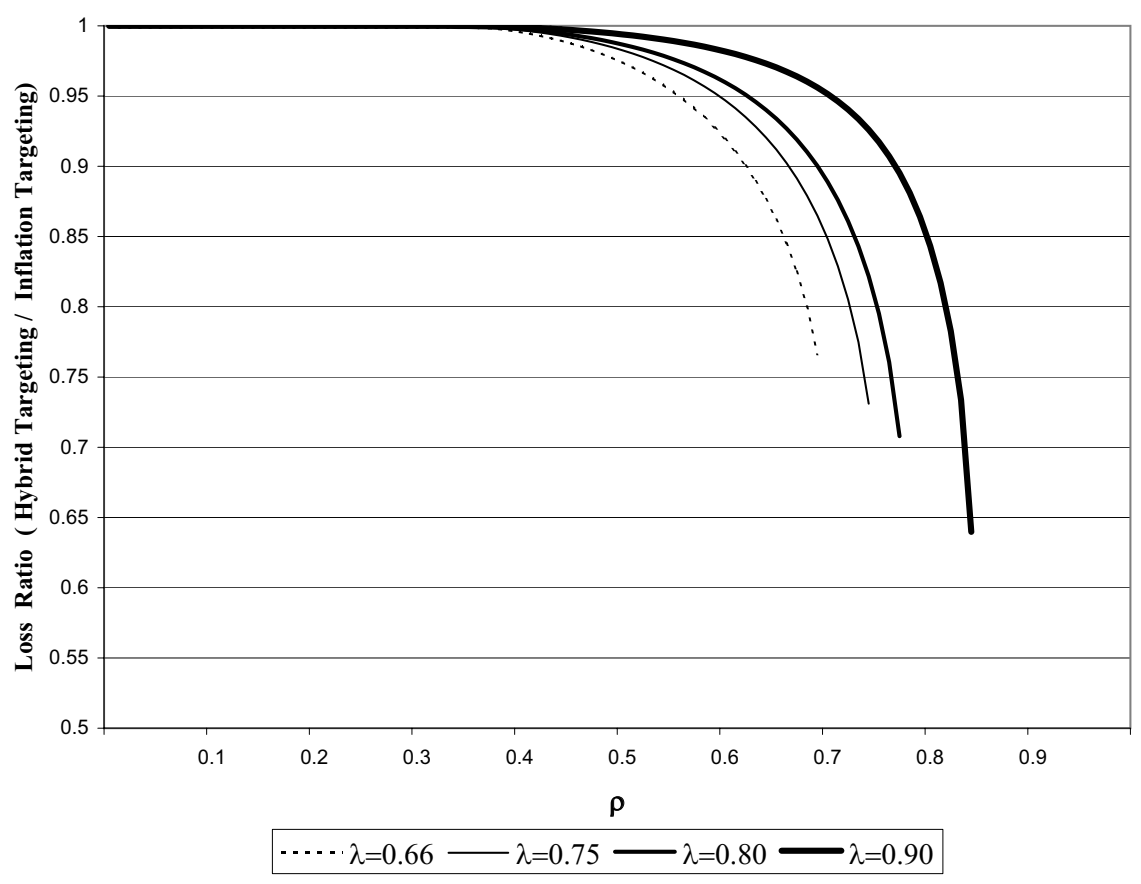


$\alpha=0.5$ and $\beta=0.99$. Taken together, these give us a striking picture of the potential benefits from adopting various regimes. First, note from Figure 2.A that even if $\rho$ is very small, and so the optimal regime is close to one of pure inflation targeting, the loss from adopting price-path targeting is small. Only when $\lambda$ is set to $2 / 3 \mathrm{rds}$, a relatively low value, and when output has virtually no persistence does a move from price-path targeting to the optimal hybrid imply a welfare gain of as much as 10 percent.

This is in stark contrast with Figure 2.B, where we see the consequences of shifting from a pure inflation targeting regime to the optimal hybrid. As output persistence rises above 0.6 , the ratio of the losses starts to decrease very quickly. (Note that the lines end at the point where the restriction (11) is no longer met.) That is, the gain from moving from inflation targeting to the optimal hybrid can be very large. To use Svensson's terminology, there is a "free lunch" and it can be big. And since we are unsure how big $\rho$ really is, it is likely prudent to move to price-path targeting.

\section{Conclusion}

We have examined whether a country is well-advised to target inflation, target the price path, or doing something in between. The issue turns on the persistence of output deviations from their trend. With high persistence, which is what we tend to observe, our theoretical results suggest that countries are best off if they adopt a hybrid target that is close to price-path targeting. But such a policy regime would be difficult to adopt for two reasons. First, there is the technical one. The exact targeting procedure depends on the estimation of both the output trend and output persistence, both of which are going to be measured with substantial error. And second, the success or failure of any monetary policy regime rests critically on the ability of central bankers to communicate what they are doing to the public. Explaining a 
hybrid target would be challenging for even the best central bankers.

Taking these problems into account, we examine the welfare loss from adopting pure inflation or price-path targeting rather than the optimal hybrid. Our conclusion is that price-path targeting is less risky, in that the maximum social loss from being wrong - choosing price-path targeting when something else is better - is much smaller than if one chooses inflation targeting. 


\section{Appendix}

\section{A.1 Data Description}

All data are quarterly beginning in 1980 Q1. For EMU countries, data are through 1998 Q4. For non-EMU countries, data are through 2001 Q4.

1. Prices: Consumer Price Index from the IMF International Financial Statistics.

2. Output: Industrial Production from the IMF International Financial Statistics, except for Portugal and Ireland, which are entirely from the OECD; New Zealand is from the OECD for 2000 Q3 on; Italy is from OECD for 2001 Q1 on; and Chile is manufacturing production only.

3. Core Consumer Prices: From the OECD

4. Import Prices: The import price index from the IMF International Financial Statistics, except for Spain, New Zealand, Netherlands, Canada, France, Ireland, Israel, Italy where the Unit Value of Imports from IFS is used; Mexico Import Price Index from Haver Analytics; Austria uses the German CPI; and Portugal is an equally weighted average of the CPIs for the UK, Spain, France and Germany.

5. Inflation targets are computed from the "Inflation Targeting Country Fact Sheets" by Frank Gaenssmantel of the Institute of International Economics, courtesy of Edwin Truman. The target $p_{t}^{*}$ is computed as follows

$$
\begin{aligned}
& p_{t}^{*}=p_{t-1}+\pi^{*} \\
& p_{t}=\log \left(C P I_{t}\right)-p_{t}^{*} \quad \text { when there is } p_{t}^{*} \\
& p_{t}=\log \left(C P I_{t}\right)-H \text { Ptrend } \quad \text { otherwise }
\end{aligned}
$$


Table A.1: Annual Inflation Target

\begin{tabular}{|c|c|c|}
\hline Country & Period & "Inflation Target \\
\hline Australia & "1993 Q1 - 2001 Q4 & $2.5 \%$ \\
\hline Austria & 1993 Q1 - 2001 Q4 & $2.0 \%$ \\
\hline \multirow[t]{2}{*}{ Canada } & 1992 Q1 - 1994 Q4 & $4.0 \%$ \\
\hline & 1995 Q1 - 2001 Q4 & $3.0 \%$ \\
\hline \multirow[t]{11}{*}{ Chile } & 1991 Q1 - 1991 Q4 & $18.0 \%$ \\
\hline & 1992 Q1 - 1992 Q4 & $17.5 \%$ \\
\hline & 1993 Q1 - 1993 Q4 & $11.0 \%$ \\
\hline & 1994 Q1 - 1994 Q4 & $10.0 \%$ \\
\hline & 1995 Q1 - 1995 Q4 & $8.0 \%$ \\
\hline & 1996 Q1 - 1996 Q4 & $7.0 \%$ \\
\hline & 1997 Q1 - 1997 Q4 & $6.0 \%$ \\
\hline & 1998 Q1 - 1998 Q4 & $5.0 \%$ \\
\hline & 1999 Q1 - 1999 Q4 & $4.3 \%$ \\
\hline & $2000 \mathrm{Q} 1-2000 \mathrm{Q} 4$ & $3.5 \%$ \\
\hline & $2001 \mathrm{Q} 1-2001 \mathrm{Q} 4$ & $3.0 \%$ \\
\hline Finland & 1993 Q1 - 2001 Q4 & $2.0 \%$ \\
\hline \multirow[t]{9}{*}{ Israel } & 1992 Q1 - 1992 Q4 & $14.5 \%$ \\
\hline & 1993 Q1 - 1993 Q4 & $10.0 \%$ \\
\hline & 1994 Q1 - 1994 Q4 & $8.0 \%$ \\
\hline & 1995 Q1 - 1995 Q4 & $9.5 \%$ \\
\hline & 1996 Q1 - 1996 Q4 & $9.0 \%$ \\
\hline & 1997 Q1 - 1997 Q4 & $8.5 \%$ \\
\hline & 1998 Q1 - 1999 Q4 & $4.0 \%$ \\
\hline & $2000 \mathrm{Q} 1-2000 \mathrm{Q} 4$ & $3.5 \%$ \\
\hline & $2001 \mathrm{Q} 1-2001 \mathrm{Q} 4$ & $3.0 \%$ \\
\hline \multirow[t]{3}{*}{ Korea } & 1999 Q1 - 1999 Q4 & $3.75 \%$ \\
\hline & $2000 \mathrm{Q} 1-2000 \mathrm{Q} 4$ & $2.5 \%$ \\
\hline & 2001 Q1 - 2001 Q4 & $3.0 \%$ \\
\hline \multirow[t]{7}{*}{ Mexico } & 1995 Q1 - 1995 Q4 & $19.0 \%$ \\
\hline & 1996 Q1 - 1996 Q4 & $20.5 \%$ \\
\hline & 1997 Q1 - 1997 Q4 & $15.0 \%$ \\
\hline & 1998 Q1 - 1998 Q4 & $12.0 \%$ \\
\hline & 1999 Q1 - 1999 Q4 & $13.0 \%$ \\
\hline & $2000 \mathrm{Q} 1-2000 \mathrm{Q} 4$ & $10.0 \%$ \\
\hline & $2001 \mathrm{Q} 1$ - $2001 \mathrm{Q} 4$ & $6.5 \%$ \\
\hline \multirow[t]{2}{*}{ New Zealand } & 1992 Q1 - 1996 Q4 & $1.0 \%$ \\
\hline & 1997 Q1 - 2001 Q4 & $1.5 \%$ \\
\hline Norway & $2001 \mathrm{Q} 1-2001 \mathrm{Q} 4$ & $2.5 \%$ \\
\hline U.K. & 1992 Q1 - 2001 Q4 & $2.5 \%$ \\
\hline
\end{tabular}

Source: Frank Gaenssmantel, "Inflation Targeting Country Fact Sheets," mimeo., Institute of International Economics, 2002. 
where $\pi^{*}$ is the annual inflation target in the following table, divided by four. When the target is a range,the midpoint is used.

\section{A.2 The Commitment Case}

Our solutions in the text assume that the central bank operates under discretion. Discretion means that policymakers reoptimize the loss function every period after observing the state variable $y_{t-1}$ and the shock $\epsilon_{t}$. The alternative to this is commitment, in which the central bank optimizes once and commits to an instrument rule once and for all.

To find the commitment solution we take the derivative of the central bank's loss (5) with respect to $p_{t}$ and $p_{t}^{e}$, subject to the constraint imposed by the Phillips curve (6). The resulting policy rule, the equivalent to equation (8), is

$$
p_{t}=\eta p_{t-1}+\tilde{c} \epsilon_{t}
$$

where

$$
\tilde{c}=-\frac{\tilde{D}}{1+\alpha \tilde{D}} \quad \text { and } \quad \tilde{D}=\frac{\alpha(1-\lambda)}{\lambda\left(1-\rho^{2} \beta\right)}
$$

This is exactly the same as the case under discretion considered in Section 2.1, except that $b=0$. That is, under commitment the optimal response is to react only to the past price level and the shock, not to $y_{t-1}$. And recall that the condition for a solution to exist under discretion, shown in (11), arises in computing $b$, and so is not present here.

Continuing with the problem under commitment, society's loss, the equivalent to (13), is now

$$
\tilde{L}^{S}=\left[\frac{2 \lambda \tilde{c}^{2}}{1+\eta}+\frac{1-\lambda}{1-\rho^{2}}\left(\frac{\tilde{c}}{\tilde{D}}\right)^{2}\right] \sigma_{\epsilon}^{2}
$$


The $\eta$ that minimizes this loss is trivially 1 , which implies inflation targeting. Under commitment, it is optimal to simply give the central bank society's loss function.

\section{A.3 When Society Prefers Price-Path Targeting}

What if society's preferences are in terms of the path of the price level rather than an inflation target? In this case, the central bank's problem is the same as the one in Section 2.1. It is the social loss, (12), that changes. Assuming society cares about the price path implies that the social loss function is

$$
L^{S}=\lambda \sigma_{p}^{2}+(1-\lambda) \sigma_{y}^{2}
$$

Substituting in the solution for the central bank's problem, this becomes

$$
L^{S}=\left[\lambda D^{2}\left(\frac{1}{1-\eta^{2}}\right)\left(\frac{1+\eta \rho}{1-\eta \rho}\right)+(1-\lambda)\right] \sigma_{y}^{2} .
$$

Equation (A.7) is the equivalent to text equation (13). The optimal $\eta$ that minimizes this loss is 0 . So, if society cares about the price-path, then the central bank should be told to care about it, too.

\section{A.4 Substituting Core for Headline Consumer Prices}

The following tables are from substituting measures of the core CPI for the headline CPI in the computations of Section 3. Table A.2 is the analog to text Table 2 and Table A.3 is the analog to text Table 4. Note that since the output equations (16) and (19) do not include the price level, the estimates of $\rho$ and $\eta^{*}$ are unchanged, and so the corresponding columns in the tables are identical. Comparing these results to those in the text, we conclude that sustituting core for headline prices changes little. 
Table A.2: Optimal Hybrid-Targeting Regime: Closed Economy with Core CPI

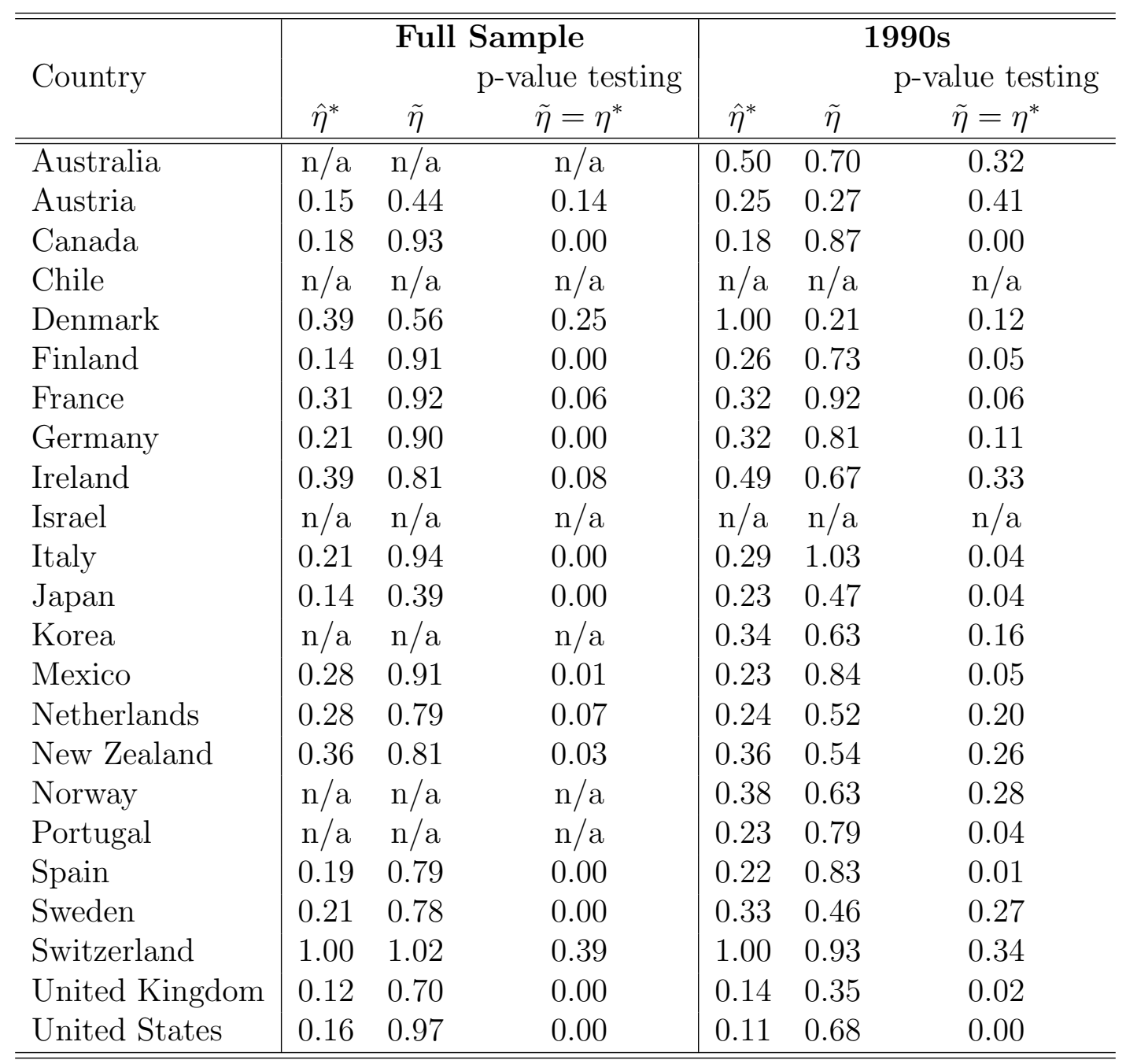

See notes to text Table 2 and Appendix A.1. 
Table A.3: Optimal Hybrid-Targeting Regime: Open Economy with Core CPI

\begin{tabular}{l|ccc|ccc}
\hline \hline \multirow{2}{*}{ Country } & \multicolumn{3}{|c|}{ Full Sample } & \multicolumn{3}{c}{ 1990s } \\
& & \multicolumn{2}{c}{$\begin{array}{c}\text { p-value testing } \\
\text { p-value testing }\end{array}$} \\
& $\hat{\eta}^{*}$ & $\tilde{\eta}$ & $\tilde{\eta}=\eta^{*}$ & $\hat{\eta}^{*}$ & $\tilde{\eta}$ & $\tilde{\eta}=\eta^{*}$ \\
\hline \hline Australia & $\mathrm{n} / \mathrm{a}$ & $\mathrm{n} / \mathrm{a}$ & $\mathrm{n} / \mathrm{a}$ & 0.37 & 0.72 & 0.21 \\
Austria & 0.09 & 0.26 & 0.23 & 0.29 & 0.17 & 0.45 \\
Canada & 0.17 & 0.94 & 0.00 & 0.19 & 0.88 & 0.00 \\
Chile & $\mathrm{n} / \mathrm{a}$ & $\mathrm{n} / \mathrm{a}$ & $\mathrm{n} / \mathrm{a}$ & $\mathrm{n} / \mathrm{a}$ & $\mathrm{n} / \mathrm{a}$ & $\mathrm{n} / \mathrm{a}$ \\
Denmark & 0.31 & 0.44 & 0.29 & 1.00 & 0.05 & 0.35 \\
Finland & 0.13 & 0.91 & 0.00 & 0.14 & 0.70 & 0.01 \\
France & $\mathrm{n} / \mathrm{a}$ & $\mathrm{n} / \mathrm{a}$ & $\mathrm{n} / \mathrm{a}$ & 0.33 & 0.93 & 0.08 \\
Germany & 0.19 & 0.87 & 0.00 & 0.21 & 0.86 & 0.07 \\
Ireland & 0.53 & 0.79 & 0.24 & 0.32 & 0.58 & 0.25 \\
Israel & $\mathrm{n} / \mathrm{a}$ & $\mathrm{n} / \mathrm{a}$ & $\mathrm{n} / \mathrm{a}$ & $\mathrm{n} / \mathrm{a}$ & $\mathrm{n} / \mathrm{a}$ & $\mathrm{n} / \mathrm{a}$ \\
Italy & 0.19 & 0.83 & 0.01 & 0.25 & 0.93 & 0.02 \\
Japan & 0.18 & 0.37 & 0.01 & 0.35 & 0.45 & 0.26 \\
Korea & $\mathrm{n} / \mathrm{a}$ & $\mathrm{n} / \mathrm{a}$ & $\mathrm{n} / \mathrm{a}$ & 0.29 & 0.62 & 0.15 \\
Mexico & 0.26 & 0.95 & 0.01 & 0.42 & 0.89 & 0.20 \\
Netherland & 0.26 & 0.79 & 0.09 & 0.30 & 0.42 & 0.37 \\
New Zealand & 0.34 & 0.82 & 0.02 & 0.28 & 0.51 & 0.19 \\
Norway & $\mathrm{n} / \mathrm{a}$ & $\mathrm{n} / \mathrm{a}$ & $\mathrm{n} / \mathrm{a}$ & 0.24 & 0.69 & 0.14 \\
Portugal & $\mathrm{n} / \mathrm{a}$ & $\mathrm{n} / \mathrm{a}$ & $\mathrm{n} / \mathrm{a}$ & 0.16 & 0.75 & 0.05 \\
Spain & 0.18 & 0.79 & 0.00 & 0.17 & 0.77 & 0.00 \\
Sweden & 0.19 & 0.76 & 0.00 & 0.26 & 0.46 & 0.21 \\
Switzerland & 1.00 & 1.02 & 0.41 & 1.00 & 0.94 & 0.33 \\
United Kingdom & 0.11 & 0.71 & 0.00 & 0.13 & 0.34 & 0.01 \\
United States & 0.14 & 0.94 & 0.00 & 0.10 & 0.69 & 0.00 \\
\hline \hline
\end{tabular}

See notes to text Table 4 and Appendix A.1. 


\section{References}

Batini, Nicoletta and Anthony Yates, "Hybrid inflation and Price Level Targeting," Bank of England Working Paper No. 135, (May 2002).

Cecchetti, Stephen G. and Michael Ehrmann, "Does Inflation Targeting Increase Output Volatility? An International Comparison of Policymakers" Preferences and Outcomes' in Norman Loayza and Klaus Schmidt-Hebbel (editors), Monetary Policy: Rules and Transmission Mechanisms, Proceedings of the Fourth Annual Conference of the Central Bank of Chile, Santiago, Chile: Central Bank of Chile, (2002), 247-274.

Cecchetti, Stephen G., Alfonso Flores-Lagunes and Stefan Krause, "Has Monetary Policy Become More Efficient?" unpublished manuscript, (May 2002).

Clark, Peter B., Charles A.E. Goodhart and Haizhou Huang "Optimal Monetary Policy Rules in a Rational Expectations Model of the Phillips Curve," Journal of Monetary Economics, 43 (1999), 497-520.

Dittmar, Robert and William T. Gavin, "What Do New-Keynesian Phillips Curves Imply for Price-Level Targeting?" Economic Review of the Federal Reserve Bank of St. Louis (April 2000), 21-30.

Dittmar, Robert, William T. Gavin and Finn Kydland, "The Inflation-Output Variability Trade-off and Price-Level Targeting," Economic Review of the Federal Reserve Bank of St. Louis (1999) 23-39.

King, Mervyn, 'Challenges for Monetary Policy: New and Old,' in New Challenges for Monetary Policy, Proceedings of the Federal Reserve Bank of Kansas City Symposium (1999).

Mankiw, N. Gregory and Ricardo Reis, "Sticky Information vs. Sticky Prices: A Proposal to Replace the New Keynesian Phillips Curve," N.B.E.R. Working Paper No. 8290, May 2001.

Mishkin, Frederic S., "Inflation Targeting," in Howard Vane and Brian Snowdon, Encyclopedia of Macroeconomics (Edward Elgar: London, forthcoming)

Parkin, Michael, "A Note on Inflation Targeting versus Price Level Targeting," Department of Economics, University of Western Ontario (2000). 
Rogoff, Kenneth, "The Optimal Degree of Commitment to an Intermediate Monetary Target," Quarterly Journal of Economics 100 (1985), 1169-1190.

Söderlind, Paul, "Solution and Estimation of RE Macromodels with Optimal Policy," European Economic Review 43 (1999), 813-823.

Svensson, Lars E.O., "Price Level Targeting vs. Inflation Targeting," Journal of Money, Credit and Banking 31 (August 1999), 277-295.

Svensson, Lars E.O., "Open-economy Inflation Targeting," Journal of International Economics 50 (February 2000), 155-183.

Rudebusch, Glenn D. and Lars E.O. Svensson, "Policy Rules for Inflation Targeting," in John B. Taylor, ed., Monetary Policy Rules, Chicago, Ill.: University of Chicago Press for the NBER (1999).

Vestin, David, "Price Level Targeting vs. Inflation Targeting in a Forward-Looking Model,"Working Paper No. 106, Sveriges Riksbank, (May 2000). 